\title{
First report of chronic implant-related septic arthritis and osteomyelitis due to Kytococcus schroeteri and a review of human $K$. schroeteri infections
}

\author{
J. F. W. Chan · S. S. Y. Wong $\cdot$ S. S. M. Leung $\cdot$ \\ R. Y. Y. Fan - A. H. Y. Ngan - K. K. W. To • \\ S. K. P. Lau $\cdot$ K.-Y. Yuen · P. C. Y. Woo
}

Received: 30 November 2011 / Accepted: 9 February 2012/Published online: 6 March 2012

(C) The Author(s) 2012. This article is published with open access at Springerlink.com

\begin{abstract}
We report the first case of Kytococcus schroeteri implant-related septic arthritis and osteomyelitis, identified by phenotypic tests and $16 \mathrm{~S}$ rRNA sequencing, which responded to implant removal and doxycycline. 16S rRNA sequencing was useful for the accurate and rapid identification of the organism as it exhibited three different colonial morphologies in vitro.
\end{abstract}

Keywords Kytococcus schroeteri - Arthritis .

Osteomyelitis · Implant · Infection

\section{Introduction}

The genus Kytococcus, literally meaning "a coccus from skin”, was separated from Micrococcus spp. in 1995 based

J. F. W. Chan - S. S. Y. Wong - S. S. M. Leung

R. Y. Y. Fan · A. H. Y. Ngan · K. K. W. To ·

S. K. P. Lau - K.-Y. Yuen - P. C. Y. Woo

Department of Microbiology, Queen Mary Hospital, Pokfulam,

Hong Kong SAR, China

S. S. Y. Wong · K. K. W. To · S. K. P. Lau - K.-Y. Yuen ·

P. C. Y. Woo

State Key Laboratory of Emerging Infectious Diseases,

The University of Hong Kong, Pokfulam, Hong Kong SAR, China

S. S. Y. Wong · K. K. W. To - S. K. P. Lau - K.-Y. Yuen ·

P. C. Y. Woo

Research Centre of Infection and Immunology, The University of Hong Kong, Pokfulam, Hong Kong SAR, China

S. S. Y. Wong · K. K. W. To - S. K. P. Lau - K.-Y. Yuen ·

P. C. Y. Woo $(\bowtie)$

Carol Yu Centre for Infection, The University of Hong Kong, 102 Pokfulam Road, Pokfulam, Hong Kong SAR, China

e-mail: pcywoo@hkucc.hku.hk on phylogenetic and chemotaxonomic properties [1]. Kytococci are Gram-positive, pigmented, non-encapsulated, non-motile, aerobic, catalase-positive cocci in pairs or tetrads. The genus now consists of three species: $K$. sedentarius, $K$. schroeteri, and K. aerolatus. Sporadic cases of prosthetic valve endocarditis and pneumonia in immunocompromised patients due to K. schroeteri have been described, but to the best of our knowledge, we report here the first case of chronic implant-related septic arthritis with contiguous osteomyelitis caused by a strain of $K$. schroeteri which exhibited three different colonial morphologies in vitro.

\section{Case report}

A 45-year-old Chinese man who suffered from left shoulder dislocation requiring tendon reconstruction with a silicone graft 15 years previously presented with recurrent flare-ups of chronic left shoulder infection manifesting as increasing pain and discharge. He first experienced left shoulder pain and discharge 6 years earlier, at which time a firm subcutaneous mass at the left acromioclavicular joint and a discharging sinus at the coracoid process of the left scapula were detected on physical examination. The roentgenogram showed an old fracture with callus formation at the distal left clavicle. Ultrasonography of the left shoulder showed an inflammatory mass measuring $46 \times 9 \times 20 \mathrm{~mm}$ in the subcutaneous tissues overlying the acromioclavicular joint. This mass communicated with a second mass overlying the coracoid process, the lateral aspect of the pectoralis muscle, and extended to the glenohumeral joint. A sinogram detected a sinus tract, approximately $7 \mathrm{~cm}$ in length, which extended superomedially, with its cephalic end located just below the coracoid process of the left scapula. Culture of the debrided wound tissue yielded methicillin-sensitive 
Staphylococcus aureus, and the patient was treated with a 2-week course of cloxacillin. However, his symptoms recurred 1 year later. Computerized tomography scan of the left shoulder showed diffuse bony sclerosis and pus in the sinus tract extending from the skin surface to the old fracture site at the distal left clavicle and left acromioclavicular joint. Repeated debridement was performed, and culture of the debrided tissue yielded "Micrococcus spp." Despite initial response, the patient's condition worsened again after another 2 years. Magnetic resonance imaging showed both an enhancing lesion in the left distal clavicle extending into the overlying subcutaneous fat and a non-enhancing mass, suspected to be surgical material, within the lesion. In view of the recurrent symptoms despite repeated wound debridement and cloxacillin, a more extensive operation consisting of ostectomy, joint lavage, wound debridement, and removal of the implanted silicone graft, was performed.

Aerobic culture of the debrided bone yielded tiny nonhemolytic colonies of Gram-positive cocci in tetrads and clusters on 5\% sheep blood agar after $24 \mathrm{~h}$ of incubation in $5 \% \mathrm{CO}_{2}$ at $37^{\circ} \mathrm{C}$. After $48-72 \mathrm{~h}$ of incubation, colonies with three different types of morphologies became apparent on macroscopic observation (Fig. 1). Morphotype 1 was muddy yellow, dry, rough, and volcano-like, had irregular edges, and measured about $2.5 \mathrm{~mm}$ in diameter. Morphotype 2 had a lighter yellow color and smooth edges, was pleomorphic, and measured about $0.5-1.5 \mathrm{~mm}$ in diameter. Morphotype 3 had a chalky yellow color, was tiny, and measured about $0.5-1 \mathrm{~mm}$ in diameter. All three morphotypes tested positive for catalase, arginine dihydrolase, alkaline phosphatase, and pyrazinamidase, and negative for oxidase, lecithinase, $\beta$-galactosidase, and urease. They hydrolyzed gelatin and Tween 80 , but not esculin. The API Rapid ID 32 Strep (bioMérieux, Marcy l'Etoile, France) and the BD Phoenix automated microbiology (Becton-Dickinson Diagnostics, Sparks, MD) systems identified all three morphotypes to be "Micrococcus spp." with $99 \%$ confidence levels. Scanning electron microscopy, performed as described in our previous publications [2, 3], showed spherical cells measuring around $1.0 \mu \mathrm{m}$ in tetrads or clusters.

In view of their phenotypic differences from micrococci, namely, resistance to penicillin and oxacillin, and positive arginine dihydrolase activity, 16S rRNA gene sequencing was performed, as described in our previous publications for other Gram-positive cocci [4-6], using LPW1282 5'-GCGTGCTTAACACATGCAAG-3' and LPW58 5'-AG GCCCGGGAACGTATTCAC-3' (Sigma-Proligo, Singapore) as the PCR and sequencing primers. The sequences of the PCR products were compared with sequences of closely related species in the GenBank by multiple sequence alignment using ClustalX 1.83 [7], and phylogenetic relationships were determined using the neighborjoining method. Sequencing of the 16S rRNA gene of the morphotypes showed that the 16S rRNA gene sequences of the three morphotypes were identical. There was no base difference between the 16S rRNA gene sequence of the three morphotypes and that of K. schroeteri (GenBank Accession No. GU180084.1), 12 (1.3\%) base differences between the 16S rRNA gene sequence of the morphotypes and that of $K$. aerolatus (GenBank Accession No. FM992368.1), and 15 (1.6\%) base differences between the 16S rRNA gene sequence of the morphotypes and that of K. sedentarius (GenBank Accession No. EU379289.1), confirming that all three morphotypes were $K$. schroeteri (Fig. 2).

Antimicrobial susceptibility tests were performed by the disk diffusion method (Bio-Rad, Hercules, CA) on Mueller-Hinton agar. The results were expressed as susceptible, intermediate, or resistant according to the criteria of the Clinical and Laboratory Standards Institute (CLSI) for staphylococci [8]. All three morphotypes were resistant to
Fig. 1 Appearances of Kytococcus schroeteri morphotypes 1, 2, and 3 in $5 \%$ sheep blood agar after $72 \mathrm{~h}$ of incubation in $5 \% \mathrm{CO}_{2}$ at $37^{\circ} \mathrm{C}$. a, b Morphotype 1, c, d morphotype 2, e, f morphotype 3

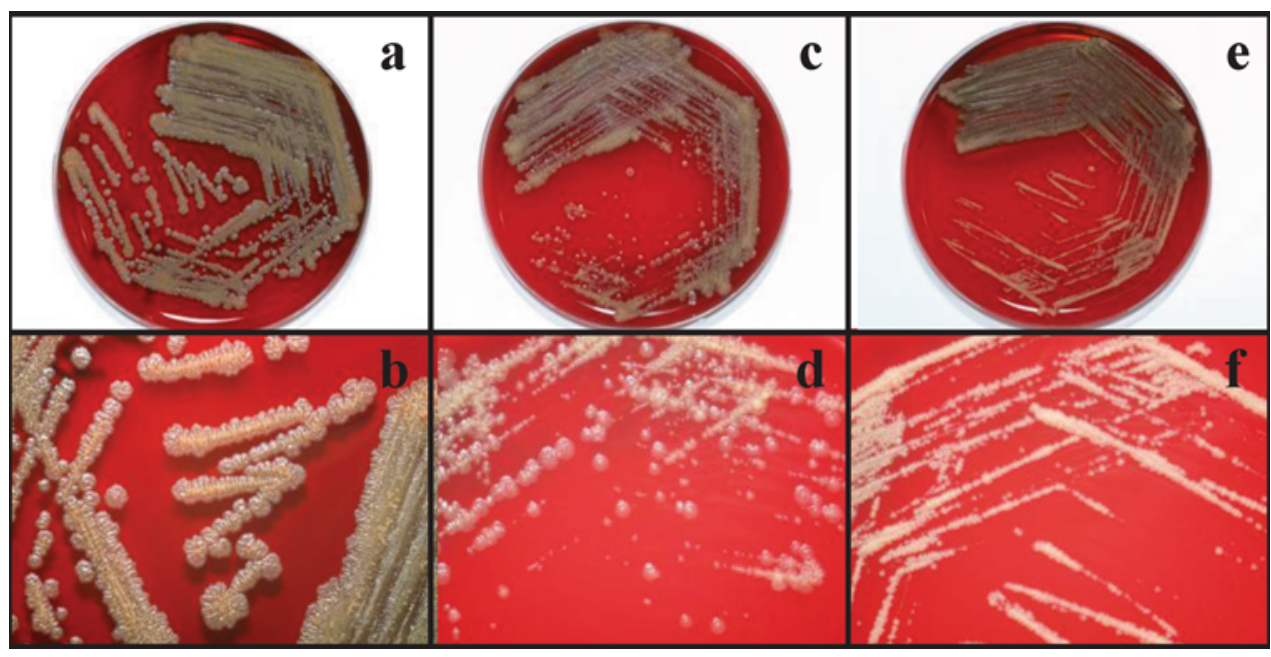




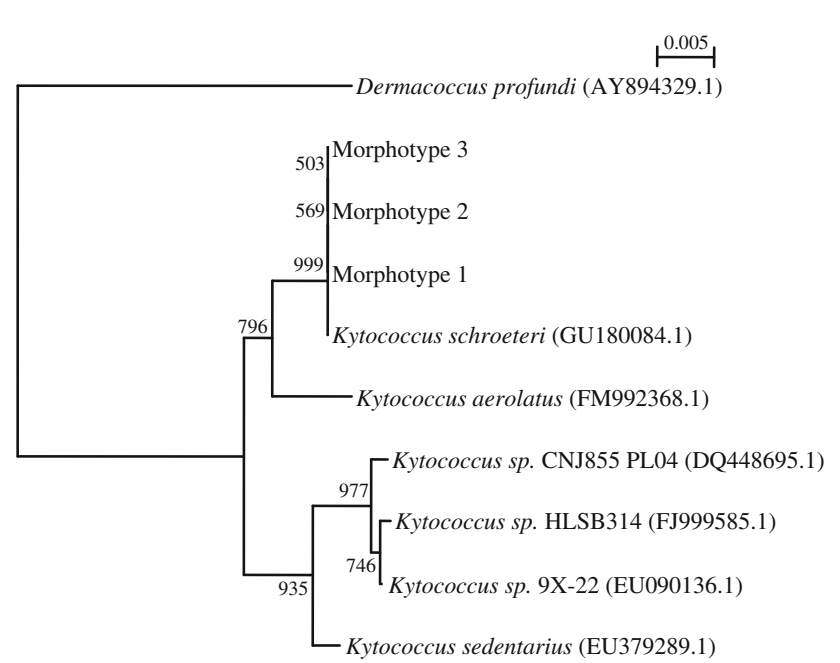

Fig. 2 Phylogenetic tree showing the relationships of the three morphotypes to closely related species. The tree was inferred from $16 \mathrm{~S}$ rRNA gene sequence data by the neighbor-joining method and rooted using the 16S rRNA gene sequence of Dermacoccus profundi (AY894329.1). Bootstrap values were calculated from 1,000 trees. The scale bar indicates the estimated number of substitutions per 200 bases. Names and accession numbers are given as cited in the GenBank database

penicillin, oxacillin, cefuroxime, clindamycin, and fusidic acid and were susceptible to amoxicillin/clavulanate, minocycline, rifampicin, and vancomycin.

Postoperatively, the patient was treated with a 6-week course of oral doxycycline $100 \mathrm{mg}$ every $12 \mathrm{~h}$. He had good clinical response, and the symptoms and raised inflammatory markers resolved after 1 week. He had remained well at the follow-up 3 years after the operation.

\section{Discussion}

Traditionally, the different colonial appearances among the three Kytococcus spp. is considered to be a direct and helpful property by which to differentiate them. Whilst $K$. sedentarius is classically described as having a "deep buttercup yellow" or "cream-white" color [1], K. schroeteri is known for its "muddy yellow" pigmentation [9]. $K$. aerolatus, which has yet to be implicated in human infection, has a beige pigmentation [10]. Our case describes a novel and important laboratory observation of $K$. schroeteri: the existence of different colonial morphologies within the same organism. As shown in Fig. 1, colonies with three different macroscopic morphologies were isolated from our patient. In this situation, the macroscopic appearance of the colonies was not reliable tool to differentiate the organisms from other pigmented Kytococcus spp. Although various physiological properties and fatty acid compositions may be useful to separate the three species of Kytococcus, the results are often inconclusive and the analyses time-consuming. In contrast, the application of 16S rRNA gene sequencing allows rapid and accurate identification of the organisms. Using this technique, we identified all three morphotypes from our patient as $K$. schroeteri. Taking into account their similar scanning electron microscopic appearances, biochemical properties, and identical 16S rRNA gene sequences, we concluded that all three morphotypes belonged to the same strain of $K$. schroeteri and that this strain possessed different colonial morphologies.

In addition to generating new observations on the organism's microbiological characteristics, our case also carries significant clinical impact in being the first case of $K$. schroeteri chronic implant-related septic arthritis with contiguous osteomyelitis. After its first isolation from the blood of a patient with prosthetic valve endocarditis in 2002 [9, 11], the clinical significance of $K$. schroeteri has been increasingly recognized in the past decade. Including our case, a total of 14 cases of $K$. schroeteri-related infections have been reported in the literature (Table 1), namely, six (43\%) cases of prosthetic valve endocarditis [9, 11-16], five (36\%) cases of pneumonia [17-20], one (7\%) case of ventriculoperitoneal shunt infection [21], one case (7\%) of folliculitis [19], one case (7\%) of infective spondylodiscitis [22], and our case of chronic implantrelated septic arthritis with contiguous osteomyelitis. The most common site of isolation of the organism was the blood $(9 / 14 ; 64 \%)$, followed by respiratory tract secretions $(5 / 14 ; 36 \%)$, bone $(2 / 14 ; 14 \%)$, prosthetic heart valve $(1 / 14 ; 7 \%)$, and cerebrospinal fluid $(1 / 14 ; 7 \%)$. Among the patients who did not have an infection of a prosthesis, the majority $(5 / 6 ; 83 \%)$ had an immunocompromised state (use of prednisolone or acute myeloid leukemia). The other patient with lumbar spondylodiscitis developed the infection after an operation which compromised the local immunity [22]. Thus, similar to coagulase-negative staphylococci and micrococci, $K$. schroeteri is regarded as an opportunistic pathogen which is capable of causing prosthesis-related infections, skin infection, osteomyelitis, and fatal pneumonia in immunocompromised hosts. The prognosis of patients with $K$. schroeteri-related infections mainly depend on the clinical presentation and immune status of the patient. All five patients with pneumonia were immunocompromised, and the majority of them $(4 / 5 ; 80 \%)$ died within 1 month despite supportive treatment. The nine patients with other forms of clinical manifestations (infection of prostheses or lumbar spondylodiscitis) recovered with antibiotics and surgical removal of prostheses. Unlike coagulase-negative staphylococci and micrococci, however, the natural habitat of $K$. schroeteri has not been confirmed to be the human skin and mucous membranes. Szczerba and Krzeminski [23] isolated $K$. sedentarius, but not $K$. schroeteri, from human skin and 


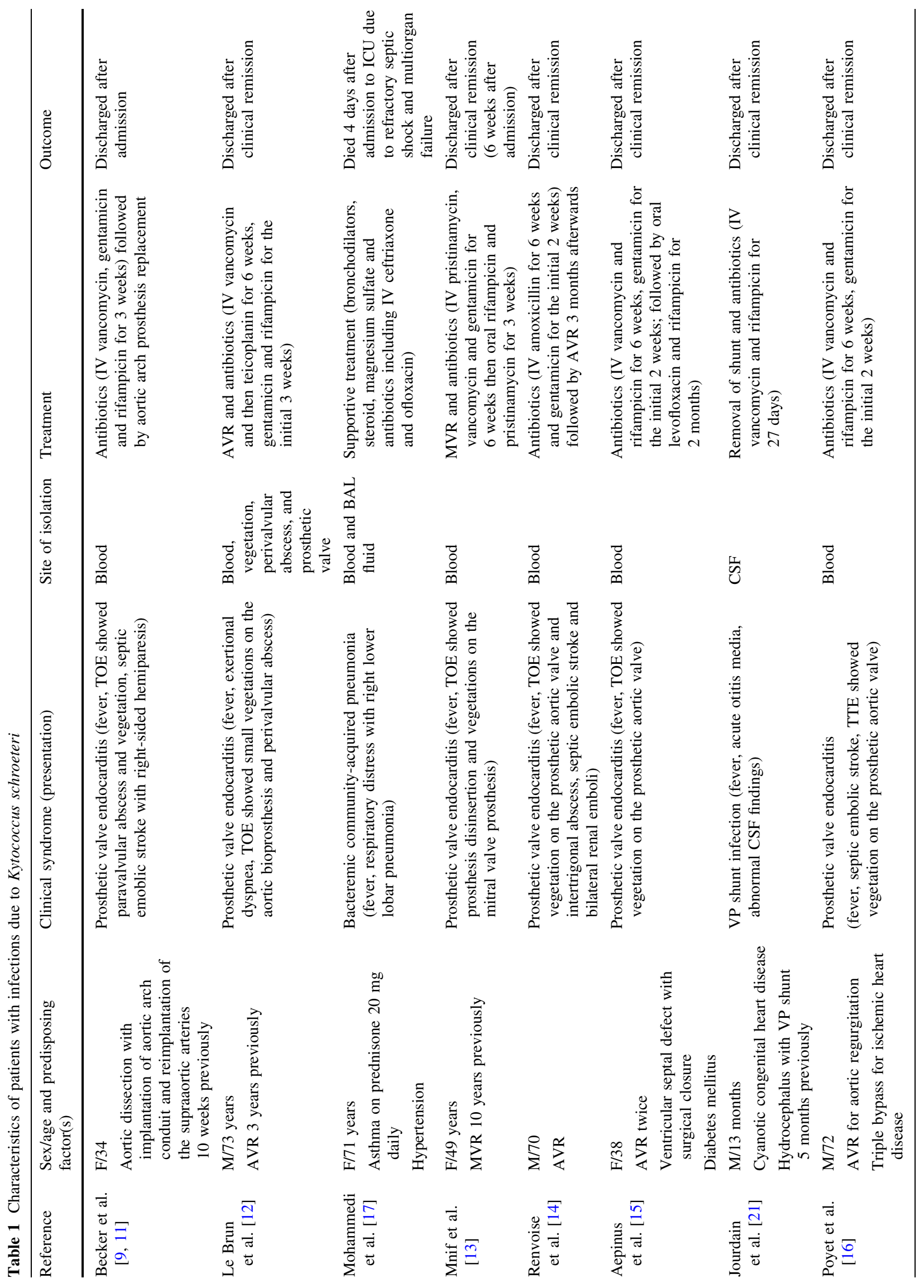




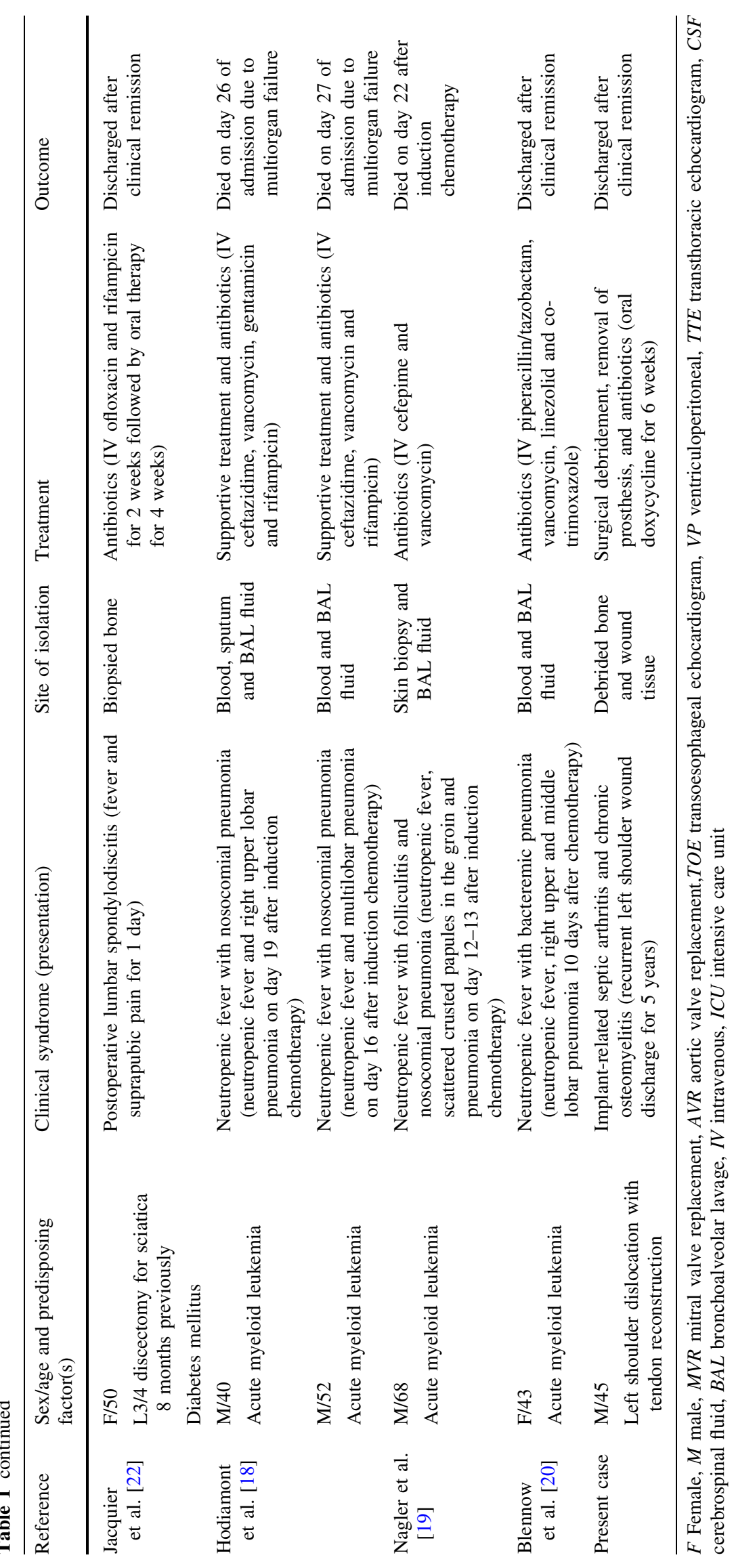


mucous membranes. Le Brun [12] and colleagues were also unable to recover $K$. schroeteri from the skin and mucous membranes of their patient. However, at the time of Szczerba and Krzeminski's study, K. schroeteri was probably unrecognized. Thus, further sampling should be performed to assess whether $K$. schroeteri, like K. sedentarius, is part of the skin and mucous membranes flora.

In terms of antibiotic susceptibilities, K. schroeteri is frequently resistant to penicillin $\mathrm{G}$ (unlike micrococci) and oxacillin [9], a property which is considered to be specific for the genus Kytococcus. This is of clinical importance as these antibiotics are often used as first-line agents in cases of musculoskeletal infections caused by coagulase-negative staphylococci and micrococci. In such cases, empirical antibiotics consisting of ampicillin and cloxacillin are often used. The exact antibiotic susceptibility patterns are frequently omitted unless there is suboptimal clinical response to empirical treatment. As an illustration of this, the chronicity and the extent of disease involvement in our patient would probably have been less if further identification and antibiotic susceptibility tests had been performed on the initially isolated "Micrococcus spp." to optimize the choice of antibiotics, rather than at the time when the patient suffered from progressive disease despite treatment with cloxacillin. Due to the scarcity of cases, there is no standardized guideline for the optimal choice of antibiotics in K. schroeteri-related infections. Because of the frequent occurrence of prosthesis-related infections in the reported case series, glycopeptides, namely, vancomycin and teicoplanin, in combination with aminoglycosides and rifampicin, were often required in the initial parenteral phase. Oral antibiotics, including fluoroquinolones and tetracyclines, with or without the addition of rifampicin, were used as oral maintenance depending on the individual strains' susceptibilities, clinical severity, and the presence or absence of prostheses.

In summary, in our case report we describe two important novel findings of $K$. schroeteri: the existence of variable colonial morphologies and its capability to cause chronic implant-related joint and bone infection. Other clinical entities commonly associated with $K$. schroeteri include prosthetic valve endocarditis and fatal pneumonia in immunocompromised patients. Therefore, in patients who have prosthesis or are immunocompromised, further analysis to identify this potentially pathogenic organism using 16S rRNA gene sequencing should be performed after initial isolation of coagulase-negative staphylococci or micrococci in the laboratory. Treatment consisting of appropriate antibiotics and removal of infected prostheses is often necessary to prevent significant morbidities and mortalities.

\section{Nucleotide sequence accession number}

The 16S rRNA gene sequences of the morphotypes have been lodged within the GenBank sequence database under Accession Numbers JF514888-JF514890.

Acknowledgments This work is partly supported by the University Development Fund and the Committee for Research and Conference Grant, The University of Hong Kong.

\section{Conflict of interest None.}

Open Access This article is distributed under the terms of the Creative Commons Attribution License which permits any use, distribution, and reproduction in any medium, provided the original author(s) and the source are credited.

\section{References}

1. Stackebrandt E, Koch C, Gvozdiak O, Schumann P. Taxonomic dissection of the genus Micrococcus: Kocuria gen. nov., Nesterenkonia gen. nov., Kytococcus gen. nov., Dermacoccus gen. nov., and Micrococcus Cohn 1872 gen. emend. Int J Syst Bacteriol. 1995;45:682-92. Erratum in: Int J Syst Bacteriol 46:366

2. Woo PC, Tam DM, Leung KW, Lau SK, Teng JL, Wong MK, Yuen KY. Streptococcus sinensis sp. nov., a novel Streptococcus species isolated from a patient with infective endocarditis. J Clin Microbiol. 2002;40:805-10.

3. Woo PC, Tse H, Lau SK, Leung KW, Woo GK, Wong MK, Yuen KY. Alkanindiges hongkongensis sp. nov. A novel Alkanindiges species isolated from a patient with parotid abscess. Syst Appl Microbiol. 2005;28:316-22.

4. Woo PC, Fung AM, Lau SK, Wong SS, Yuen KY. Group G beta-hemolytic streptococcal bacteremia characterized by $16 \mathrm{~S}$ ribosomal RNA gene sequencing. J Clin Microbiol. 2001;39: 3147-55.

5. Woo PC, Tam DM, Lau SK, Fung AM, Yuen KY. Enterococcus cecorum empyema thoracis successfully treated with cefotaxime. J Clin Microbiol. 2004;42:919-22.

6. Woo PC, Tse H, Wong SS, Tse CW, Fung AM, Tam DM, Lau SK, Yuen KY. Life-threatening invasive Helcococcus kunzii infections in intravenous drug users and ermA-mediated erythromycin resistance. J Clin Microbiol. 2005;43:6205-8.

7. Thompson JD, Gibson TJ, Plewniak F, Jeanmougin F, Higgins DG. The CLUSTAL_X windows interface: flexible strategies for multiple sequence alignment aided by quality analysis tools. Nucleic Acids Res. 1997;25:4876-82.

8. Clinical and Laboratory Standards Institute (CLSI). Performance standards for antimicrobial susceptibility testing; twenty-first informational supplement. CLSI Document M100-S21, vol 31 (ISBN 1-56238-742-1). CLSI, Wayne; 2010

9. Becker K, Schumann P, Wüllenweber J, Schulte M, Weil HP, Stackebrandt E, Peters G, von Eiff C. Kytococcus schroeteri sp. nov., a novel Gram-positive actinobacterium isolated from a human clinical source. Int J Syst Evol Microbiol. 2002;52: 1609-14.

10. Kämpfer P, Martin K, Schäfer J, Schumann P. Kytococcus aerolatus sp. nov., isolated from indoor air in a room colonized with moulds. Syst Appl Microbiol. 2009;32:301-5. 
11. Becker K, Wüllenweber J, Odenthal HJ, Moeller M, Shumann P, Peters G, von Eiff C. Prosthetic valve endocarditis due to Kytococcus schroeteri. Emerg Infect Dis. 2003;9:1493-5.

12. Le Brun C, Bouet J, Gautier P, Avril JL, Gaillot O. Kytococcus schroeteri endocarditis. Emerg Infect Dis. 2005;11:179-80.

13. Mnif B, Boujelbène I, Mahjoubi F, Gdoura R, Trabelsi I, Moalla S, Frikha I, Kammoun S, Hammami A. Endocarditis due to Kytococcus schroeteri: case report and review of the literature. J Clin Microbiol. 2006;44:1187-9.

14. Renvoise A, Roux V, Casalta JP, Thuny F, Riberi A. Kytococcus schroeteri, a rare agent of endocarditis. Int J Infect Dis. 2008;12: 223-7.

15. Aepinus C, Adolph E, von Eiff C, Podbielski A, Petzsch M. Kytococcus schroeteri: a probably underdiagnosed pathogen involved in prosthetic valve endocarditis. Wien Klin Wochenschr. 2008;120:46-9.

16. Poyet R, Martinaud C, Pons F, Brisou P, Carlioz R. Kytococcus schroeteri infectious endocarditis. Med Mal Infect. 2010;40: 51-3.

17. Mohammedi I, Berchiche C, Becker K, Belkhouja K, Robert D, von Eiff C, Etienne J. Fatal Kytococcus schroeteri bacteremic pneumonia. J Infect. 2005;51:11-3.
18. Hodiamont CJ, Huisman C, Spanjaard L, van Ketel RJ. Kytococcus schroeteri pneumonia in two patients with a hematological malignancy. Infection. 2010;38:138-40.

19. Nagler AR, Wanat KA, Bachman MA, Elder D, Edelstein PH, Schuster MG, Rosenbach M. Fatal Kytococcus schroeteri infection with crusted papules and distinctive histologic plump tetrads. Arch Dermatol. 2011;147:1119-21.

20. Blennow O, Westling K, Fröding I, Ozenci V. Pneumonia and bacteraemia due to Kytococcus schroeteri. J Clin Microbiol. 2012;50:522-524.

21. Jourdain S, Miendje Deyi VY, Musampa K, Wauters G, Denis O, Lepage P, Vergison A. Kytococcus schroeteri infection of a ventriculoperitoneal shunt in a child. Int J Infect Dis. 2009;13: $153-5$.

22. Jacquier H, Allard A, Richette P, Ea HK, Sanson-Le Pors MJ, Berçot B. Postoperative spondylodiscitis due to Kytococcus schroeteri in a diabetic woman. J Med Microbiol. 2010;59:127-9.

23. Szczerba I, Krzeminski Z. Occurrence and number of bacteria from the Micrococcus, Kocuria, Nesterenkonia, Kytococcus and Dermacoccus genera on skin and mucous membranes in humans. Med Dosw Mikrobiol. 2002;55:67-74. 